\title{
Case Studies of e-Infrastructure Adoption
}

Link to publication record in Manchester Research Explorer

\section{Citation for published version (APA):}

Barjak, F., Kertcher, Z., Poschen, M., Lane, J., Procter, R., \& Robinson, S. (2008). Case Studies of e-Infrastructure Adoption. In 4th International Conference on e-Social Science

\section{Published in:}

4th International Conference on e-Social Science

\section{Citing this paper}

Please note that where the full-text provided on Manchester Research Explorer is the Author Accepted Manuscript or Proof version this may differ from the final Published version. If citing, it is advised that you check and use the publisher's definitive version.

\section{General rights}

Copyright and moral rights for the publications made accessible in the Research Explorer are retained by the authors and/or other copyright owners and it is a condition of accessing publications that users recognise and abide by the legal requirements associated with these rights.

\section{Takedown policy}

If you believe that this document breaches copyright please refer to the University of Manchester's Takedown Procedures [http://man.ac.uk/04Y6Bo] or contact uml.scholarlycommunications@manchester.ac.uk providing relevant details, so we can investigate your claim.

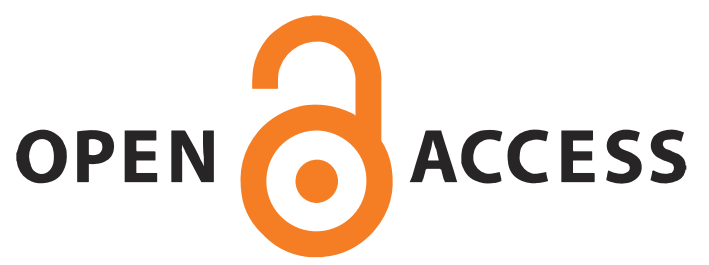




\title{
Case Studies of e-Infrastructure Adoption
}

\author{
Franz Barjak ${ }^{1}$, Julia Lane ${ }^{2}$, Zack Kertcher ${ }^{2}$, Meik Poschen ${ }^{3}$, Rob Procter ${ }^{3}$, \\ Simon Robinson ${ }^{4}$ \\ ${ }^{1}$ University of Applied Sciences Northwestern Switzerland \\ ${ }^{2}$ National Opinion Research Center at the University of Chicago (NORC), USA \\ ${ }^{3}$ National Centre for e-Social Science (NCeSS), UK \\ ${ }^{4}$ empirica Communication and Technology Research, Germany \\ Email address of corresponding author: franz.barjak@fhnw.ch
}

We report results from a study of e-Infrastructure adoption in the social sciences and the humanities ( $\mathrm{SSH})$. We find that bridging barriers between computer and domain scientists is of key importance. In particular, SSH communities have to be accepted as being distinct and not suited to a "one size fits all" strategy of e-Infrastructure diffusion. As expected, sustainability was also a core issue, whereas barriers to resource sharing could mostly be resolved with technological solutions, and skills and training activities are a reflection of the general "user dilemma". Our recommendations to EU policy-makers point the way to promoting e-Infrastructure development and application in SSH fields.

\section{Introduction}

By and large, neither in Europe nor in the United States have social sciences and humanities (SSH integrated e-Infrastructure into their research practices (c.f. Catlett, 2006; Vanneschi, 2005). Little is known on what affects this adoption, as Woolgar summarizes:

"Despite the enormous unfolding investment in eg grid technologies, it seems we know almost nothing about how and why (and by whom) these new technologies will be taken up, nor what will be the likely effects on the nature and conduct of e-Science and e-Social Science research." (Woolgar, 2003, 1)

Several reports predict enormous scientific and social payoffs from a large-scale adoption of e-Infrastructure in the SSH (e.g. ACLS, 2006; Berman \& Brady, 2005; ESRC, 2004), because of the potential to collect, link, access and analyze data on a scale transcending what has been possible in the past. However, adoption of ICTs in science is clearly "not just a matter of time" (Kling \& McKim, 2000). e-Infrastructure is usually not included among the core concerns and questions of SSH fields, but an activity of a few researchers with a particular technical inclination or computationally demanding research interests; it may even be considered an external intervention resulting from the interaction with computer scientists and engineers (Wouters \& Beaulieu, 2007). Looking at e-Infrastructure from this perspective, it seems more appropriate to consider adoption as the result of localized negotiation processes under influences of a social, technological, scientific, cultural, economic and political nature. The present paper tries to shed some light on these influences and investigates the factors that support or hamper the uptake of e-Infrastructure among SSH researchers. It investigates, in particular, why e-Infrastructure projects in SSH succeed or fail. It draws on exploratory data 
collected for the European Commission within the "Accelerating Transition to Virtual Research Organization in Social Science (AVROSS)" study. ${ }^{1}$

For AVROSS we adopted the e-infrastructure definition promoted by the e-Infrastructure Reflection Group (e-IRG) which defined e-infrastructure as integrated ICT-based research infrastructure (Leenaars, Heikkurinen, Louridas, \& Karayannis, 2005). Key elements include networking infrastructure, middleware and organization and various types of resources (such as supercomputers, sensors, data and storage facilities). Though the definition includes "old" components like supercomputers, the World Wide Web or e-mail, it requires that these be part of an integrated system before they become part of e-infrastructure. The basic requirement for any component is that it should be able to exchange information through a standardized interface or protocol.

\section{Social shaping of e-Infrastructure for the social sciences and humanities}

Opposing deterministic conceptions of the relationship between technology and society and replacing linear models of innovation by evolutionary perspectives, a set of models has been developed that can be summarised under the notion of "social shaping of technology" (SST). The overriding strength of these approaches is that they ask how "technology" comes to be "technology". Common characteristics are that they do not conceive of technology as exogenous, or fixed by "nature" alone, but shaped also by non-technical factors (Edge, 1995; MacKenzie \& Wajcman, 1999; Williams \& Edge, 1996). Relationships between social groups, material objects, and other components of the socio-technical networks are crucial in the development of new technology (Edwards et al., 2007; Fleck, 1994; Fleck, Webster, \& Williams, 1990; Molina, 1997). Social shaping describes this process as an alternation of variation and selection, replacing the linear order of invention, innovation and diffusion. An innovation is not considered as a fixed product, process or organisational configuration that is diffused if it matches the requirements of the potential adopters as in diffusion studies (Rogers, 1995). Rather, SST highlights that a new technology will still be shaped and reconfigured during innovation and diffusion, what has been called "innofusion" (Fleck, 1988) or "situated innovation" (Dittrich, Eriksén, \& Wessels, 2003). We distinguish in this study between the following influences on this process of shaping e-Infrastructure:

i. Links between technology developers and users

ii. Technical skills and training

iii. Communities

iv. Barriers to sharing resources

v. Funding

Links between technology developers and users: A major contribution of SST approaches is that it brought the users back into the picture. There are several aspects to this relationship. The features that developers bestow on and users expect in e-Infrastructure are influenced by what they perceive as feasible and desirable. These perceptions depend not least on the capacities of previous technologies which are used for the same or similar purposes. A "technological frame" or "technological paradigm" determines what the involved social groups perceive. It is a combination of current theories, tacit knowledge, engineering practice, specialized testing procedures, goals, and handling and using practice that determines problem perception and acceptable solution strategies (Bijker, 1987). Any new technological solution needs to be communicated and negotiated among developers and users on the grounds of their (often differing) technological paradigms.

1 See http://plattformen.fhnw.ch/avross. 
Insufficient linking between technology developers and users has been a particular problem of IT development and e-Infrastructure has been no exception (Berman \& Brady, 2005; Voss et al., 2007). Though the involvement of committed users has been a standard practice in eInfrastructure development, this is not, in itself, sufficient to ensure that prototypes are ready for deployment more widely. First, requirements identified by early users may not be representative of the requirements of the wider user community. Second, they may be more tolerant of limitations in new tools and services, being prepared, for example, to work around 'bugs', or to cope with poor usability. Third, agendas of computer scientists and researchers from the user domains are difficult to reconcile. The computer scientists wish to push the state of the art in their field, whereas the domain researchers wish to see progress in delivering solutions (Lawrence, 2006). We expect that the more profoundly e-Infrastructure projects manage to connect with their user constituencies, the better will be their uptake.

Technical skills and training: e-Infrastructure users cannot realize their ideas without mastering the technology. Among SSH researchers, the ability to formalize ideas and convert them into code is not common. e-Infrastructure projects in the SSH thrive and have a better chance to make an impact if they either have a "support infrastructure" of technology developers or widespread training measures or - ideally - both.

Educating and training developers to engage with users from the SSH and training the latter to work with e-Infrastructures contributes to the "intellectual sustainability" (ACLS Commission on Cyberinfrastructure for the Humanities and Social Sciences, 2006, p. 28) of eInfrastructure. The necessity to increase grid and other e-Infrastructure related training has been stressed for all scientific domains and by different organizations. ${ }^{2}$

Communities: One of the key arguments of SST is that a new technology is not a black box, but is shaped by the demands of the community.

"A social shaping perspective, however, focuses on the ongoing dynamic between a technology and a community, as the technology is developed, used, shaped, reconfigured, and reconstituted within the community." (Kling \& McKim, 2000, p. 1311)

The use of whatever application and technology will often not depend on individual interests, but institutional and community requirements and practices (Voss et al., 2007). eInfrastructure might be functional for some activities which are realized collaboratively in a community, e.g., the building of a joint on-line database, the distribution of new findings in a repository, whereas others are typically done non-collaboratively, like the use and analysis of data (Anderson \& Carlson, 2006). Some scholarly communities still attach little value to collaboration and rely on single author work or simply do not need technological tools for collaborating (ACLS, 2006).

It has been argued that the variety of these practices and, in particular, the difference between fields in the soft sciences and the hard sciences has not been taken into account sufficiently in the building of e-Infrastructure. Wouters and Beaulieu $(2006,2007)$ find a misalignment between the emerging e-Science community and SSH communities in regard to the culture, habits, customs and organizational setting. Field-specific practices, conventions and standards have developed over decades and scientists tend to be sceptical and unwilling if somebody tells them that they have to change, in particular, if that somebody is considered to be an outsider without expert knowledge in the field. A different turn to e-Science should be considered: one that changes the focus from "electronic science" to "enhanced research"

2 Training is an issue in e-Science in general and substantial concerns about sufficient numbers of trained individuals for the full exploitation and maintenance of e-Social Science investments have been frequently expressed (e.g., e-IRG in Leenaars, et al., 2005; OGF at http://www.ogf.org/gf/group_info/view.php? group=et-cg; see also unpublished summary reports NSF/SBE cyberinfrastructure workshops Sept 18, 2004 and Oct 22, 2004 and survey results from ESRC review of NCeSS hub, 2005, in the UK). 
(Wouters \& Beaulieu, 2007), starting at the analysis of different research fields, with particular research practices, communication and collaboration relations, and a specific social organization, to find out how their differing needs can be supported by new ICTs (Hodgson \& Clark, 2007; Woolgar, 2003; Wouters \& Beaulieu, 2006, 2007). Being supported by communities of domain scientists is not only necessary for an adequate definition of needs and technology development, but also for acquiring funds and making infrastructure sustainable in the long term (Avery, 2007).

Barriers to sharing resources: Another important and systemic aspect is the multiple barriers to sharing resources, such as data and software. Data in the SSH is often complex, tacit, fuzzy, discursive, inconsistent, and subject to privacy and ownership concerns (Carlson \& Anderson, 2007). It might need substantial amounts of metadata to be intelligible and usable by others than the producers and still loose a lot in the process of digitization. All this leads to large costs for preparing data for shared use. At the same time, virtually no scientific credit is allocated for sharing datasets. In addition, ownership rights in data generated in a collaborative project might be difficult to assign, yet the data themselves may have substantial financial value. Another problematic issue lies in the systemic dependence of new applications on their development context and the problems of re-embedding and interoperability which accrue in transfers (Voss et al., 2007). We expect that solutions to these problems of sharing resources and in particular data will have a significant effect on the dissemination of an e-Infrastructure.

Funding: The role of (future) costs and benefits certainly exerts an important influence on the shape and success of an innovation in market economies (MacKenzie \& Wajcman, 1999). Costs of development, market introduction, and production, return on investment, expected sales price compared to older technologies and competing solutions are all economic categories which influence the decision of the involved groups in an innovation project. Moreover, in order for social scientists to invest time and energy in e-social science, they need to be convinced that the tools that they are using will not become rapidly obsolete. Hardening and sustaining research products is difficult because products are heterogeneous, the process is costly, and researchers are trained to break new ground, rather than sustain existing projects. Standardization could solve the concern by (potential) users about the sustainability of new tools and the resulting interoperability (Kahin, 2007). This is, of course, a fundamental issue in e-science more broadly.

\section{Data and methods}

One of the main empirical contributions of AVROSS was based on an analysis of eight case studies identified as promising SSH e-Infrastructure projects. For the selection of the interviewees from the cases, a snowball sampling was used aiming at the following groups: $\mathrm{PI}(\mathrm{s})$, researchers, developers, users and (if it made sense and was applicable) involved stakeholders like National Grid Service (UK), JISC, TeraGrid, D-Grid or similar related eInfrastructure projects or service/technology groups. For each case study, several face-to-face or telephone interviews with the main initiators, providers and managers of the projects were conducted.

The interviews were conducted as semi-structured interviews in which a smaller body of open-ended questions was combined with questions which were based on probes, follow-ups, and case specific items. The semi-structured interview approach permitted exploring the conceptual linkages among the sources of influence on the shaping of technology, as well as potentially identifying new ones. The constructs can be used to understand how funding is related to mobilization, how e-Infrastructure shapes existing socio-technical practices, and the ways in which this framework has been shaped by existing socio-political institutions, for example. 
Regarding influences on e-Infrastructure development, the interview guideline took SST perspectives into account, namely technological frames and user requirements, scientific shaping of technology, economic factors, and political influences Additionally, the following points had to be considered:

- Challenges and difficulties projects had to master in their different phases from the invention to the introduction and dissemination among the user community

- Modifications to the initial objectives, key current applications and benefits to the users and possible future developments which might further increase the usability and benefits

- Possibilities of, or experiences with, transferring the project from the initial work environment and community for which it was made to other environments

Archival materials were another central data component which complemented interviews in order to enable a comprehensive analysis of the case studies. Both published and internal project material was obtained from different sources such as the interview partners, project websites or other sites containing project descriptions and presentations.

The case studies were documented in case descriptions of on average 6 pages (3-8 pages). These case descriptions were subsequently condensed and compared along the main dimensions of the analysis.

\section{Selected cases}

Due to the advanced state of e-Social Science in the UK and the US, three of the eight cases were taken from the UK and two from the US. Another three cases are from other EU countries.

Table I: Overview of the AVROSS case studies

\begin{tabular}{lccc}
\hline Project & Country & Domain & Technology \\
\hline Access Grid Support Centre - AGSC & UK & Multi & $\begin{array}{c}\text { conferencing and } \\
\text { collaboration tool }\end{array}$ \\
\hline Modelling and Simulation for e-Social Science - MoSeS & UK & SS & simulation portal \\
\hline Communication Data ComDAT (pseudonym) & US & SS & data repository \\
\hline Simulation Portal - SPORT (pseudonym) & US & SS & simulation portal \\
\hline $\begin{array}{l}\text { Understanding New Forms of Digital Records for e- } \\
\text { Social Science - DReSS }\end{array}$ & UK & SS & data repository \\
\hline Documentation of Endangered Languages - DOBES & NL & Hum & data repository \\
\hline TextGrid & DE & Hum & data repository \\
\hline FinGrid (pseudonym) & EU country & SS & data repository \\
\hline Source: AVROSS.
\end{tabular}

Source: AVROSS.

Among the case studies, five have a focus on the generation of data repositories including tools and applications for regulating access as well as managing and processing the data (ComDAT, DReSS, DoBeS, TextGrid, and FinGrid). Of these five, four are still in the development phase and only one (FinGrid) has been ended. Two further projects (SPORT and $\mathrm{MoSeS}$ ) use data for modeling and simulating socio-economic events and processes. The eighth project, the AGSC, is a support service for users who use the AccessGrid (AG), a conferencing and collaboration application. 


\section{Influences on e-Infrastructure adoption}

\section{Links between technology developers and users}

The case studies either address a broad user community from several SSH fields and beyond (AGSC) or focus on one specific field for which the applications are being or have been developed. Projects in early stages (SPORT, ComDAT, MoSeS, DReSS, and TextGrid) rely on pilot users and work with prototypes and testbeds. Only two projects had large user communities at the time of data collection: AGSC is to some extent a special case offering free services to users of a proprietary technology and DoBeS has a large user community among the language researchers of the languages included in the project. For the other projects the establishment of a user community was still an open and critical issue for success.

The strategies for recruiting users were in nearly all cases rather weak and under developed: projects tend to rely on what is offered by their funding or institutional environment, e.g., DReSS relying mainly on NCeSS activities. In some cases, the developers and PIs expected that word-of-mouth advertising at conferences or other events would do the trick. However, the FinGrid project, which has been discontinued (not the least for failing to attract a user community), shows that this is not enough. Another weakness seems to be that user-developer interaction is the main focus of user-related activities. However, this is not enough for making the merits of e-Infrastructure visible to potential users. In addition to user-developer interaction, more user-user interaction would be required, for instance pilot users presenting showcases to potential users or PIs disseminating their results in the user domains.

In several cases, the often negative experiences of (pilot) users led project leaders and developers to delay large-scale roll-out (AGSC, SPORT, TextGrid, and FinGrid). These negative experiences resulted, for instance, from complex user interfaces, low stability of the applications, and difficulties in integrating existing applications and standards into new environments. Solutions to these problems were often sought in the technical sphere, e.g., redesigning user interfaces, adding and re-launching applications, quality testing programmes (AGSC) etc.

In sum, the cases mostly seem to be driven by the traditional conception of a linear sequence of invention, innovation and diffusion. Users are perceived as such and not as co-developers with a different background and perspective.

\section{Technical skills and training}

Skills and training issues are relevant in the investigated cases from two different perspectives: 1) projects need technical developers who are also able to link with the particular communities; 2) users need sufficient skills to use the e-Infrastructure.

Availability of technical developers for e-Infrastructure projects in SSH. FinGrid was the sole project with difficulties in finding staff (developers). Remarkably, DoBeS was the only project with reported regular training courses for staff, while three projects (AGSC, MoSeS, FinGrid) mentioned training taking place more informally on the job. Also, post-graduate education was of little importance within the projects: MoSeS and SPORT are the only two projects to have graduate students included in development. MoSeS was the only project to conduct formal coursework and additionally planned to implement a PhD studentship. None of the interviewees seemed to miss training in important areas.

User-oriented training. In several cases (AGSC, DReSS, DoBeS, and FinGrid), the developers and providers also engaged in training events with the users. In FinGrid they conceded, however, that the training of SSH users needed to implement a particular approach 
that took account of their lower computing skills and less structured and formalised problems. The project also developed a training tool to help users with Grid installation.

In the case studies, training activities for both staff and users were rather piecemeal and designed ad hoc to solve upcoming problems. A comprehensive and long-term strategy could be discerned in any of the cases.

\section{Communities}

Cross-disciplinary communication and collaboration. Several of the case studies struggled with communication barriers between social scientists or humanities researchers and computer scientists. These barriers place a burden on project development: specialized languages, "ping-pong" communication and differing work styles translate into differing expectations on what a project can and should achieve.

This lack of interaction and mutual understanding of domain and computer scientists goes on beyond the development phase, as SPORT interviewees highlighted: a "Throwing your research over the wall and see if anybody picked it up" attitude usually results in nobody picking it up. Field differences are still often ignored by computer scientists and developers for whom there is little difference between processing astronomical or socio-economic data (ComDAT). It is also striking that nearly all of the projects stressed close ties and involvement with the global Grid community, but not their contribution to the development of their social science or humanities "home base".

Some proposals and examples on how to deal with these communication barriers also surfaced in the case studies:

- TextGrid successfully reduced the communication barriers by involving both, domain and computer scientists, early on in the projects, letting them closely discuss the critical issues and establish a joint basis for further work.

- In DReSS the user-developer collaboration was institutionalised in the structure of the project. So-called "driver projects" intend to make sure that developments are triggered by and linked-back to user needs.

- Another solution, implemented to some extent in ComDAT, may be to engage "translators", individuals trained in both fields, who understand the language, problems and work styles of each group and can bridge communication between the involved domains.

- In MoSeS the collaboration between computer scientists and geographers worked well, as both parties had a hand in developing and being co-located helped the daily exchange of information. Users were represented by the three co-PIs (one in each application domain), who successfully collaborated with the developers to transfer user requirements and other important information.

Involving leading domain scientists in the diffusion of an e-Infrastructure and building of a user community might be a good strategy - peers and scientists in the field are the main information source on e-Infrastructure, as we learned in the AVROSS early adopter survey (Barjak et al., 2007). This should be a worthwhile but not necessarily easy undertaking: First, it should not be neglected that it still takes considerable time, as interviewees from ComDAT and SPORT pointed out, to learn and master new e-Infrastructure technologies. The necessary effort depends on both the development status of the technology as well as the technological level of the learner. Second, it should not be underestimated that, in particular, established scientists also may owe their position in part to the current infrastructural arrangements, e.g., their access to particular resources or technology (Edwards et al., 2007, pp. 26-27). Hence, 
they might not be willing to put their position at stake through supporting the diffusion of a new technology.

\section{Barriers to sharing resources}

Problems with sharing resources appeared in some of the social science cases. For two projects (SPORT, ComDAT) interviewees stated that, due to the mainly confidential nature of the data and because of the disciplinary practices, sharing is not accepted in the field. FinGrid, had to find ways between existing restrictive policies of data providers and the essential need for sharing data.

These projects encountered the issue of data protection as a major challenge. The necessity to protect data may, for instance, originate in legally binding constraints of data providers (FinGrid), from institutional regulations on (ComDAT) or from national law in case of census data, which has to be handled under strict regulations (MoSeS). The projects had to solve this issue by developing tools and applications that implemented data rights and access management - respectively in MoSeS a seamless connection of Grid and legal framework still had to be established in a feasible way at the time of the interviews. Technological solutions were possible when it came to regular numerical or textual data, though they might have required devising new applications that were not (yet) common in the broader Grid environment. However, when it comes to new types of data, like audio or video recordings in ComDAT, technological solutions for masking the identity of individuals without invalidating the recordings are less straightforward and not yet established.

The situation regarding data protection and sharing is somewhat different in the case studies mainly led by the humanities: In aiming at building libraries/archives for languages and text data both DoBeS and TextGrid naturally tend to support data sharing in order to benefit from such a practice.

\section{Funding}

Out of the eight cases, six have been funded through public R\&D grants in different research programmes. The SPORT project has been funded through institutional seed money and DoBeS through a non-profit foundation, both projects also benefit from related projects. Sustainability was an issue in all cases. The AGSC will probably be funded for at least eight years, whereas there is currently no more funding for the FinGrid project leaving a developed e-Infrastructure unsupported. The MoSeS project emerged from two pilot demonstrator projects giving the previous work some continuity.

Service-oriented business models. The success story of the AGSC confirms the value of "robust, resilient services" to academia, in particular, when it comes to supporting collaboration. An ingredient to this success seems to be that the service is offered free to users, as we also see in the ComDAT example. The TextGrid interviews also pointed in this direction, as the interviewees considered the requirement of charging individual projects and users for the service to be a major barrier of adoption in the future.

Of course, if the users themselves do not pay, alternative funding schemes need to be found that ideally provide long-term funding to secure the continuity and improvement of the service and make sure that users' investments into a technology don't get lost. The case studies do not provide any guidance on possible solutions as they are still mainly funded through public research (and development) grants. As historical studies of other infrastructures have shown, it was often public investment or funding arrangements that coupled private investment with public regulation that led to the establishment of a network (Edwards et al., 2007, p. 29). 
At the same time, users will have to commit themselves to long-term solutions and accept the service idea that comes with the technology. They will have to provide funds that cover more than the initial set-up of a technology or tool and include support and maintenance. In a networked application it affects the service level of all participants if maintenance and quality standards of one networked user are unsatisfactory and the AGSC desire of coercing AG users to conduct quality tests is hence understandable.

All projects to some extent developed applications or tools but, with the exception of FinGrid, are all still in a rather early stage. Therefore, procedures for a larger rollout of the software have not been mentioned (for FinGrid the infrastructure is in place but with no further funding future support cannot be provided). Only MoSeS explicitly referred to using open source and free software whenever possible and also developing as open source as this was also a funding requirement. Similar to the free provision of services, the free use of software under an open license could be a model to foster sustainable use - if models for the necessary further support can be found and established.

\section{Success}

We can distinguish the success and impact of the case studies with respect to the three main missions of science, 1) research, 2) teaching and 3) technology transfer.

Research. The biggest success was generally seen in addressing issues in a new way beneficial for research questions, methods and data in SSH. Here this is said to be especially true for simulation and modelling (MoSeS, SPORT), replaying and analysing new forms of digital data (DReSS) and linguistics (DoBeS). There a different categories of impact which have been identified.

- The AGSC can point to the uptake and use of AG and its own support services by various scientific communities. Projects connected to the AGSC have been funded and improvements made to $\mathrm{AG}$ and related services.

- MoSeS and SPORT have not seen the impact beyond pilot systems so far, but have evoked huge interest in various communities, which leads to new funding opportunities or concrete scenarios for future use envisioned by researchers from other domains.

- DReSS, DoBeS and TextGrid in different ways have fostered the use of digital data and repositories through new means of integration using e-Infrastructure.

- The ComDAT project has had limited impact on research due to inappropriate means for "utilizing social and behavioural data on e-Infrastructure", but reported reduction of research time and re-use of successful models for other domains.

- In the completed FinGrid project the impact on the original user community was little and shifted to creating benefits for the European Grid development community.

Teaching. Most of the projects so far have no connection to teaching or formal learning activities, but the need for e-Infrastructure "to be integrated in future curricula" (DReSS), to address this in a future work-package (TextGrid) are recognised.

Technology transfer. At the time of data collection none of the case studies had meaningful linkages to the private business sector, public administration or non-profit organizations. The AGSC had only one non-academic user; DReSS and MoSeS maintained some informal links to local public administrations who might become users of their infrastructure; the FinGrid project managed to engage an enterprise software firm that is very active in financial services in a follow-up research proposal that, however, did not obtain funding. In the other cases (ComDAT, SPORT, TextGrid, DoBeS) there was no mention of technology transfer issues. 


\section{Summary and discussion}

The challenges in achieving project goals are particularly seen in making the use as well as the funding sustainable and enlarge the user base (AGSC, ComDAT, DoBeS, TextGrid, FinGrid), followed by solving confidential and security data issues (MoSeS, SPORT) and bridging the gap between creating new prototypes for SSH and having an application which is considered to be helpful in research and will de facto be used (DReSS). Impact is rather low, as most projects are in an early phase and still have significant challenges to solve. Relating this to the other dimensions, three groups of projects can be distinguished:

- AGSC, DoBeS, and MoSeS are projects that fit rather neatly into their field communities in which they are integrated. They also have a (growing) user community and functioning user-developer interaction. This either has already shown that they can have an impact (AGSC) or puts them in a good position to make an impact as they develop.

- TextGrid and DReSS are weaker in regard to integration into the field and its practices and they have not yet advanced as far in regard to users. They also have not yet achieved an impact and they are in a weaker position for achieving this in the future.

- FinGrid, SPORT, and ComDAT are in a worse position when it comes to user-developer interaction and relations to the relevant scientific communities: they have user communities restricted to people involved in the project, no discernible strategies for acquiring more users and significant problems in linking up with potential user communities. Sharing resources seems to be also rather problematic for them. The projects are weak, too, when it comes to the realised impact on research or teaching.

Of course, this is a very much ad hoc evaluation of the case studies that does not take into account the different development stages of the projects. Therefore, the results should not be considered as conclusive, i.e., projects like SPORT and ComDAT might become accepted in their fields, and others might still fail, though the current conditions seem to be promising. However, we think that the overview is a satisfactory representation of the projects that might help to focus the activities and further development on key preconditions for success.

\section{Policy recommendations}

Although not scientific in nature (see Barjak et al., 2007), and case study analyses are inherently illustrative rather than definitive in scope, the AVROSS study did identify several key issues which are relevant for policy purposes. Social sciences and humanities can play a more active role in e-Infrastructure development if a virtuous circle at the level of eInfrastructure initiatives as well as at the level of individual projects can be generated. This virtuous circle rests on four pillars:

1. Capacity building for e-Infrastructures in the SSH: the base of motivated scientists and skilled technicians trained on e-Infrastructures needs to be broadened through education and training and funding needs both, to take the specific demands of SSH into account and to move on to sustainable funding schemes.

2. Developing appropriate tools: Tool development must be done in close, permanent and effective interaction with the users. Use barriers are lower if the users are familiar with tools which "only" have been ported on the grid environment; standardisation raises the confidence in sustainability.

3. Fostering the adoption of the approach by domain scientists: Incentives need to be given and barriers that hinder adoption need to be reduced. Such incentives should be instituted in funding schemes - e.g., to reuse existing data and make new data available through repositories - and become part of SSH research and academic practice, for instance, in 
publishing, evaluation, and promotion. Barriers often require organizational solutions as well as technical solutions, for instance, when it comes to reducing language barriers between technical developers and domain scientists.

4. Making domain scientists aware of e-Infrastructures: Awareness needs to be raised above all through demonstrating the benefits. This is most effectively done through field-specific information channels and between peers. Institutional environments, of course, need also be responsive to the pay-offs of e-Infrastructure investments. Last but not least, the knowledge of what type of infrastructure and support SSH researchers actually need and where they stand in the adoption process needs to be broadened (also raising awareness in the process of doing so).

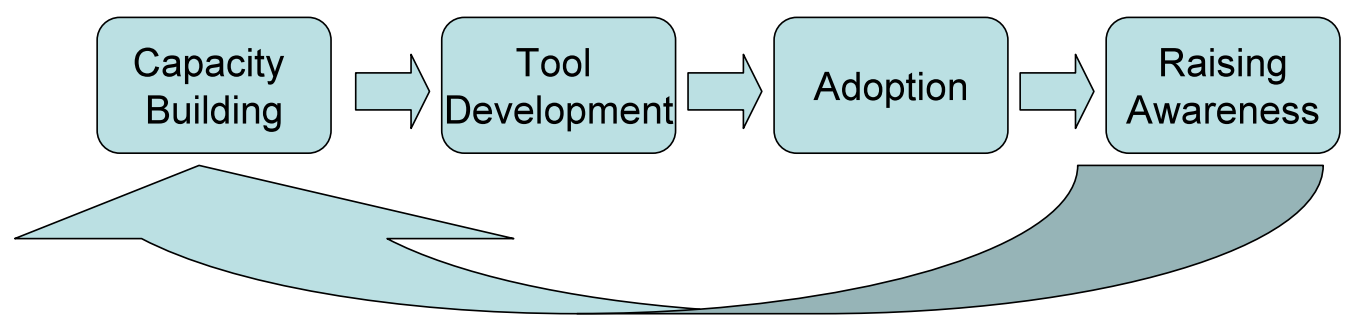

Figure 1. A virtuous cycle of e-Infrastructure in the social sciences and humanities.

Previous research has also made it clear that successful infrastructures are a combination of 'top down' and 'bottom up' processes, implying they cannot be planned in any complete sense (e.g., Edwards et al., 2007). However, we believe that the following measures will improve the chances for success at each step of the process described in the previous Figure. 
Table II: Overview of policy measures

\begin{tabular}{|c|c|c|c|}
\hline Capacity Building & Tool development & Adoption & Raising awareness \\
\hline $\begin{array}{l}\text { 1. Develop dedicated training } \\
\text { events for SSH } \\
\text { 2. Step up the role of e-Infra- } \\
\text { structure in graduate education } \\
\text { 3. Increase the use of CSCL } \\
\text { environments } \\
\text { 4. Support small-scale initiatives } \\
\text { 5. Design effective funding and } \\
\text { programme coordination } \\
\text { structures } \\
\text { 6. Fund field-specific flanking } \\
\text { measures in general, multi-dis- } \\
\text { ciplinary e-Infrastructure } \\
\text { programmes } \\
\text { 7. Support the development of } \\
\text { service-oriented business models }\end{array}$ & $\begin{array}{l}\text { 8. Involve users at } \\
\text { all stages } \\
\text { 9. Mandate user- } \\
\text { centred design } \\
\text { 10. Port existing } \\
\text { SSH tools to e- } \\
\text { Infrastructures } \\
\text { 11. Target vertical } \\
\text { areas to ensure tool } \\
\text { adoption across } \\
\text { sub-fields } \\
\text { 12. Support } \\
\text { standardisation }\end{array}$ & $\begin{array}{l}\text { 13. Institute activities to } \\
\text { promote the reuse of SSH } \\
\text { data } \\
\text { 14. Assign scientific credit } \\
\text { and ownership rights } \\
\text { 15. Reduce technical } \\
\text { barriers through providing } \\
\text { organizational solutions } \\
\text { 16. Promote under- } \\
\text { standing of SSH among } \\
\text { IT specialists } \\
\text { 17. Improve cross- } \\
\text { disciplinary communi- } \\
\text { cation and collaboration }\end{array}$ & $\begin{array}{l}\text { 18. Create supportive } \\
\text { institutional environ- } \\
\text { ments } \\
\text { 19. Increase user-user } \\
\text { interaction } \\
\text { 20. Increase the } \\
\text { information exchange } \\
\text { across projects } \\
21 . \text { Involve lead users in } \\
\text { community-building } \\
\text { 22. Institute a research } \\
\text { programme on e- } \\
\text { Infrastructures in } \mathrm{SSH}\end{array}$ \\
\hline
\end{tabular}

Source: AVROSS.

Most of these measures need further analyses and discussions in the process of operationalisation and integration into existing or new policy measures. Doing this would have gone beyond the scope of the AVROSS project.

\section{Acknowledgments}

We gratefully acknowledge the funding of the European Commission, DG Information Society and Media for "A study on requirements and options for accelerating the transition from traditional research to virtual research organisations through e-infrastructures" under EU Service Contract No. 30-CE-0066163/00-39.

\section{References}

ACLS Commission on Cyberinfrastructure for the Humanities and Social Sciences (2006). Our cultural commonwealth. New York: ACLS. Retrieved 19 December, 2006, from http://www.acls.org/cyberinfrastructure/OurCulturalCommonwealth.pdf.

Anderson, B., \& Carlson, S. (2006). Entangled Data: Knowledge \& Community making in E (Social) Science - Research Report to the ESRC. (No. 2006-15). Ipswich: Chimera, University of Essex.

Avery, P. (2007). Open Science Grid: Building and Sustaining General Cyberinfrastructure Using a Collaborative Approach [Electronic Version]. First Monday, 12. Retrieved 9. November 2006 from http://www.firstmonday.org/issues/issue12_6/avery/.

Barjak, F., Wiegand, G., Lane, J., Poschen, M., Procter, R., \& Robinson, S. (2007). Accelerating Transition to Virtual Research Organization in Social Science (AVROSS): First Results from a Survey of e-Infrastructure Adopters. Paper presented at the 3rd International Conference on e-Social Science. from http://ess.si.umich.edu/papers/paper141.pdf.

Berman, F., \& Brady, H. (2005). Final Report: NSF SBE-CISE Workshop on Cyberinfrastructure and the Social Sciences. Retrieved October 3, 2006, from: http://vis.sdsc.edu/sbe/reports/SBE-CISE-FINAL.pdf.

Bijker, W. E. (1987). The social construction of bakelite: toward a theory of invention. In W. E. Bijker, T. P. Hughes \& T. J. Pinch (Eds.), The social construction of technological systems (1 ed., pp. 159-187). Cambridge, Mass.; London: MIT Press. 
Carlson, S., \& Anderson, B. (2007). What Are Data? The Many Kinds of Data and Their Implications for Data Re-Use. Journal of Computer-Mediated Communication, 12(2), 635651.

Catlett, C. (2006). The State of TeraGrid - A National Production Cyberinfrastructure Facility. Retrieved 29 September, 2006, from http://www.teragrid.org/about/docs/StateOfTeraGrid-June2006.pdf.

Dittrich, Y., Eriksén, S., \& Wessels, B. (2003). From knowledge transfer to situated innovation. Paper presented at the Innovation in Europe: Dynamics, Institutions and Values. Retrieved 18.04.2008, from http://www.bth.se/fou/forskinfo.nsf/alfs/8778ce68e1 ead172c1256cfc00508748.

Economic and Social Research Council (2004). e-science and the Social Sciences Framework Document. Retrieved 14 April, 2008, from http://www.esrc.ac.uk/ESRCInfoCentre/Images/Escience\%20Background\%20Information tcm6-5783.pdf.

Edge, D. (1995). The social shaping of technology. In N. Heap, R. Thomas, G. Einon, R. Mason \& H. Mackay (Eds.), Information technology and society: a reader (1 ed., pp. 1432). London, Thousand Oaks, New Delhi: Sage.

Edwards, P. N., Jackson, S. J., Bowker, G., \& Knobel, C. P. (2007). Understanding infrastructure: Dynamics, tensions, and design. Report of a workshop on 'History \& theory of infrastructure: Lessons for new scientific cyberinfrastructure'. Retrieved July 29, 2007, from: http://www.si.umich.edu/ InfrastructureWorkshop/documents/UnderstandingInfrastructure2007.pdf.

Fleck, J. (1988). Innofusion or Diffusation? The nature of technological development in robotics. Edinburgh PICT Working Paper No. 7, Edinburgh University.

Fleck, J. (1994). Learning by trying: the implementation of configurational technology. Research Policy, 23(6), 637-652.

Fleck, J., Webster, J., \& Williams, R. (1990). Dynamics of information technology implementation : A reassessment of paradigms and trajectories of development. Futures, 22(6), 618-640.

Hodgson, S. M., \& Clark, T. (2007). Sociological Engagements with Computing: the Advent of E-Science and Some Implications for the Qualitative Research Community [Electronic Version]. Sociological Research Online, 12. Retrieved 16.04.2008 from http://www.socresonline.org.uk/12/3/9.html.

Kahin, B. (2007). Cyberinfrastructure and Innovation Policy [Electronic Version]. First Monday, 12. Retrieved 9. November 2006 from http://www.firstmonday.org/issues/issue12_6/kahin/.

Kling, R., \& McKim, G. (2000). Not just a matter of time: field differences and the shaping of electronic media in supporting scientific communication. Journal of the American Society for Information Science, 51(14), 1306-1320.

Lawrence, K. (2006). Walking the Tightrope: The Balancing Acts of a Large e-Research Project. Computer Supported Cooperative Work (CSCW), 15(4), 385-411.

Leenaars, M., Heikkurinen, M., Louridas, P., Karayannis, F. (2005). e-Infrastructures Roadmap. Retrieved 23 November, 2006, from http://www.e-irg.org/roadmap/eIRGroadmap.pdf.

MacKenzie, D., \& Wajcman, J. (1999). Introductory essay: the social shaping of technology. In D. MacKenzie \& J. Wajcman (Eds.), The social shaping of technology (2 ed., pp. 3-27). Buckingham; Philadelphia: Open University Press.

Molina, A. H. (1997). Insights into the nature of technology diffusion and implementation: the perspective of sociotechnical alignment. Technovation, 17(11-12), 601-626.

Rogers, E. M. (1995). Diffusion of innovations (4 ed.). New York et al.: Free Press. 
Vanneschi, M. (2005). Survey of Activities in Universities and Research Labs. Deliverable D.3.1.2 of GridCoord. Retrieved 2 Oktober, 2006 from:

http://www.gridcoord.org/grid/portal/information/public/D.3.1.2_V.1.2_181105.doc.

Voss, A., Mascord, M., Fraser, M., Jirotka, M., Procter, R., Halfpenny, P., et al. (2007). eResearch Infrastructure Development and Community Engagement. Paper presented at the UK e-Science 2007 All Hands Meeting. Retrieved 31.10.2007, from http://www.allhands.org.uk/2007/proceedings/papers/866.pdf.

Williams, R., \& Edge, D. (1996). The social shaping of technology. Research Policy, 25(6), 865-899.

Woolgar, S. (2003). Social shaping perspectives on e-science and e-social science: the case for research support. A consultative study for the Economic and Social Research Council. Retrieved 16 April, 2008, from http://www.sbs.ox.ac.uk/NR/rdonlyres/04164366-448C49B3-B359-FC55CC4A5BD6/879/ESocialScience.pdf.

Wouters, P., \& Beaulieu, A. (2006). Imagining e-science beyond computation. In C. Hine (Ed.), New Infrastructure for Knowledge Production: Understanding E-Science (pp. 4870). Hershey: Idea Group.

Wouters, P., \& Beaulieu, A. (2007). Critical accountability: dilemmas for interventionist studies of e-Science. Journal of Computer-Mediated Communication, 12(2), 583-599. 